\title{
Diamond goals not graphite! A triangulation approach to clinical teachers' needs assessment
}

\author{
Sara Heydari ${ }^{1}$, Peyman Adibi ${ }^{2}$, Athar Omid $^{1}$, Nikoo Yamani $^{1} * \mathbb{D}$ \\ Received: 23 May 2019 \\ Published: 28 Jul 2021
}

\section{Abstract}

Background: Clinical faculty development plays a significant role in the professional empowerment of future physicians. Identification of educational needs is an important step in planning faculty development. This study identified the educational needs of medical faculties in the clinical setting.

Methods: This cross-sectional needs assessment study was conducted in Iranian medical universities during 2016-2018 using a triangulation paradigm. A total of 384 medical clinical faculties, 54 medical education specialists, and 194 faculty evaluation forms completed by medical residents participated in the study using a convenient randomized sampling method. The data were gleaned with a researcher-made questionnaire with 14 areas developed on the basis of clinical education goals and contexts and were analyzed with SPSS16 using descriptive statistic indices such as mean, standard deviation, and frequency percentile. Analytical tests including independent $\mathrm{t}$-test, chi-square and Cramer's $\mathrm{V}$ were also applied $(\mathrm{p}<0.05)$. The content validity, face validity, and reliability were approved.

Results: The response rate was \%59 (227) for clinical faculties, \%77 (42) for medical education specialists, and \%58 (110) for residents. Professionalism was the first priority of needs from the viewpoint of clinical faculties and faculty development planners. The clinical teachers' highest level skills, in their own perspective and also students' perspective, were procedure training and grand round, whereas their lowest level skills were emotional intelligence and morning report. The greatest gap existed between the current skill and the need is management and leadership in the clinical setting. Cramer's index ranged between 0.18 and $0.34(p<0.05)$; hence, there was a correlation between the current status and the announced needs in all subjects.

Conclusion: Designers of faculty development programs ought to pay due attention to areas of professionalism, management, and leadership and carry out accurate and comprehensive planning to enable students to become competent future physicians in the roles of therapist, manager, teacher, supporter, and researcher.

Keywords: Needs Assessment, Faculty, Medical, Clinical Teacher, Triangulation

Conflicts of Interest: None declared

Funding: This project was funded by the National Agency for Strategic Research in Medical Education. Tehran. Iran. Grant No.960:200 and Medical Education Research Center of Isfahan University of Medical Sciences Project no. 396164.

\section{*This work has been published under CC BY-NC-SA 1.0 license.}

Copyright $@$ Iran University of Medical Sciences

Cite this article as: Heydari S, Adibi P, Omid A, Yamani N. Diamond goals not graphite! A triangulation approach to clinical teachers' needs assessment. Med J Islam Repub Iran. 2021 (28 Jul);35:96. https://doi.org/10.47176/mjiri.35.96

\section{Introduction}

The main mission of medical universities is the training

\section{Corresponding author: Dr Nikoo Yamani, yamani@edc.mui.ac.ir}

1. Department of Medical Education, Medical Education Research Center, Isfahan University of Medical Sciences, Isfahan, Iran

2. Integrative Functional Gastroenterology Research Center, Isfahan University of Medical Sciences, Isfahan, Iran of powerful, knowledgeable, creative, and responsible

\section{$\uparrow$ What is "already known" in this topic:}

To date, many studies have been conducted on the needs assessment of medical teachers. But few studies have been conducted to extract and compare the needs of different sources, including the needs of teachers and their skill levels, FDP designers, and students.

\section{$\rightarrow$ What this article adds:}

The findings of this study showed that the greatest gap between faculties' level of skills and the announced needs is management and leadership in the clinical setting. This is often overlooked in the designing FDPs. Professionalism was also the first and foremost need stated by medical teachers and FDP designers. 
scholars that commit themselves to ethical values and professional codes of ethics and enabling them to provide proper care for maintaining and promoting mental and physical health and prevention of diseases in the community $(1,2)$. The major part of this important responsibility rests on the shoulders of faculty members. They form the most important riches and the basic cornerstone of any higher education institute (3). The medical faculty members teach not only in the academia, but also in the clinical setting. Clinical training is a fundamental component of medical education, without which training of efficient and competent staff is not plausible (4). Getting professional and competent in medicine is highly dependent on the quality and quantity of clinical training (1). A great portion of this duty pertains to the clinical faculties as important models. Given the rapid changes in the healthcare setting, the more accurately and scientifically the clinical training is accomplished, the more efficient current students will be tomorrow (5).

Considering the significance of clinical training in the professional development of medical students, informing clinical faculties about various methods of clinical teaching is rendered highly mandatory. Nevertheless, most university professors, especially medical faculties, have not been formally trained in clinical teaching methods, though they are knowledgeable in clinical sciences and skills and commence teaching once they are bestowed their specialty degree; paying due attention to this issue not only promotes students' learning but also enhances the quality of patient care and focuses instructors' and learners' attention on various therapeutic aspects (6). Therefore, a benefit may be made of Faculty Development Programs (FDP) as the most important reservoir of support for these valuable riches. The new WHO guidelines not only highlight the promotion and development of scientific and technical training of healthcare staff but also emphasize that faculty development programs both promote quality and aid in training competent and motivated physicians for the $21^{\text {st }}$ century (6).

The success of such programs depends on several factors: they should be based on faculties' needs, involve them in the early years of teaching experience, demand their contribution, and warrant the continuation of the programs (7). The primary step in planning any promotion and development program for clinical faculties is developing goals on the basis of needs assessment (8). According to adult's learning theory, Knowles believes that adults should have felt a need for the subject to be learned; this feeling of personal need serves as one of the stimuli of self-directed learning (9). On the other hand, it is advisable to consider the viewpoints of beneficiaries in developing a successful FDP (10). Numerous studies have been conducted on the needs assessment of medical university faculties indicating the real needs of medical faculties in teaching domains. Adkoli (2010) reported the competencies prioritized as gaps by faculties including "knowledge of materials preparation, curriculum development, course evaluation, and research" (11). In the study by Farley et al., carried out on the educational needs of clinical faculties in emergency medicine, the topic "bedside teaching skills" gained the highest score as "self-perceived career development need" (12). The preference areas that were identified in Manzoor et al.'s research were educational psychology, teaching skills, assessment techniques, educational research, management skills, work-based ethics and conduction of meeting (13). Also, in the study by McSparron (2018), most fellows reported that though education forms an important aspect of their professional activities and that they are greatly interested in such programs, there are no mechanisms for promoting teaching skills. The study refers to the lost opportunities for developing subspecialty fellowships as future teachers (14).

The need felt for learning the teaching methods and clinical evaluation as the shared point of all needs assessment studies on clinical faculties determines the necessity of paying due attention to this important topic. Obviously, correspondence between FDP's and their real needs not only enhances the quality of teaching and treatment but also significantly influences the training of competent professional physicians for the future. The FDPs of Iranian medical universities are a unit of the Educational Development Center (EDC). The authorities of this unit are medical education specialists responsible for planning and implementing FDPs. Most studies investigate faculties' needs as self-reports; consequently, the present study surveyed the clinical faculties' needs of medical departments in Iranian medical universities with respect to clinical teaching methods from the viewpoints of faculties, FDP planners, and students. However, the needs extracted from these sources were not expected to differ significantly.

\section{Methods}

\section{Study Design and Population}

This cross-sectional study was conducted in Iranian medical universities from 2016 to 2018 using a triangulation paradigm. It is a holistic approach in which convergence, synergy, and harmony of results of research questions are achieved by applying various methodological approaches, sources, theoretical perspectives, and/or expert opinions. It has been asserted that obtaining of converging results by different approaches would increase the validity of results (15). Denzin (1978) and Patton (1999) introduced four types of triangulation: (a) method triangulation, (b) investigator triangulation, (c) theory triangulation, and (d) data source triangulation (16). In the current article, situational features were used to gather information from multiple sample sources in order to triangulate data from three different perspectives: (1) the clinical faculty of medicine, (2) FDP designers, and (3) students. Using a convenient sampling method, six "type I" and three "type II" medical universities were selected randomly. Given the unknown sample volume of the medical clinical faculty population, the sample volume was determined at 384 with a confidence interval of $\% 95$ using OpenEpi (17). The same sample volume was calculated in the Cochrane formula. Also, 54 medical specialists were selected using the purposive sampling method on the basis of faculties' managerial role and their influence on medical decision-making in these universities. Regarding faculty evaluation results, the researchers had access to the data 
of only one University. A total of 391 faculty evaluation forms were completed by residents during 2016-2017, of which 194 forms were selected with stratified random sampling from among different clinical wards (orthopedics, anesthesiology, pediatrics, surgery, internal medicine, etc.) and investigated. Of these, deficientlycompleted forms were excluded and finally, 110 questionnaires entered the study. This study used different data sources; additionally, the researchers were representatives of beneficiaries. The research team consisted of clinical faculties, the technician in charge of the FDP unit, and the technician of the faculty evaluation unit.

\section{Ethical Considerations}

This study was part of a Ph.D. dissertation at Isfahan University of Medical Sciences with the code of ethics IR.mui.rec.1396.3.164. The instructions of the questionnaires included information on the use of results of the study, and principles of information confidentiality and participant anonymity were observed. The researcher was blind to the students' and faculties' names in the faculty evaluation forms.

\section{Data Collection}

A researcher-made questionnaire was used to glean the required data. The needs assessment inventory included demographics as well as 14 items on clinical teaching methods and 1 open-ended item on other educational needs of clinical education. The items in the questionnaires were extracted from medical reference textbooks and the related published articles. Regarding the medical clinical faculties, the participants responded twice to each item listed on clinical teaching. In so doing, they expressed their opinion on their present level of skills and the amount of their need to the subject provided. Dreyfus model was used with respect to the present level of skills. We used the validated Dreyfus' 5-point scale of expertise (novice, competent, proficient, expert, and master). A 5point Likert scale was used regarding the amount of need to the topic under question ranging from "highly needed" to "not needed". The medical education specialists' questionnaires also included the same subjects using a needsassessed 5-point Likert scale ranging from "highly needed" to "not needed".

\section{Validity and Reliability}

The content validity of the questionnaire was assessed both quantitatively and qualitatively. Content validity was established qualitatively using the opinions of 10 medical specialists on the rate of correspondence between the content of the questionnaire and research goals. Moreover, to survey the content validity of the questionnaire quantitatively, the content validity index (CVI) and content validity ratio $(\mathrm{CVR})$ were applied. $\mathrm{CVI}=0.84$ and $\mathrm{CVR}=0.78$ were obtained after omitting the items that scored less than standard. Item impact score and opinions of 10 participants in the target group were used to establish face validity. The reliability of the tool was estimated at Cronbach's $\alpha \geq 0.87$ via a pilot study in which the questionnaire was administered in all three statistical popula- tions. Given the wide geographical spectrum of the samples, the questionnaire was distributed both physically and electronically.

\section{Data Analysis}

The gleaned data were analyzed with SPSS16 using descriptive statistic indices such as mean, standard deviation, and frequency percentile. Analytical tests, including independent t-test, chi-square and Cramer's V were also applied $(\mathrm{P}<0.05)$. The questionnaire was designed electronically via Google Forms so that all the questions needed to be completed online, i.e., if one question was left unanswered, the respondent could not go to the next item. As for the physical questionnaires, one of the researchers personally asked the teachers to complete all the questions in the questionnaire. Therefore, there were no missing data in this study.

\section{Results}

The response rate in the clinical teachers' questionnaire was 59\% (227 clinical teachers) and most of the samples $(68 \%)$ were males. Mean clinical teaching experience was $3.11 \pm 1.42$ years. The sample included participants of various medical fields such as internal medicine, surgery, emergency medicine, psychiatrists, pediatrics, anesthesia, etc. Most participants $(\% 29)$ belonged to internal medicine whereas the least $(\% 1)$ belonged to ophthalmology. The response rate in the medical education teachers' questionnaire was $77 \%$ (42) and most of the samples (67\%) were females. Mean work experience was $3.2 \pm 0.22$ years (Table 1).

Independent samples t-test was used to compare the scores of educational needs of clinical faculties and medical education specialists. There was a significant difference in all subjects.

Table 2 displays mean \pm SD of various sources of needs assessment. The findings indicated that professionalism was the greatest need from the perspective of clinical faculties and FDP planners. Clinical faculties stated "procedure training" as their highest level skill, while students mentioned their highest level skill in the grand round. It should be pointed out that, on the researchers' demand, the students were not asked about faculties' clinical reasoning and management in the clinical setting.

The gap between the current skill and the amount of

\begin{tabular}{lcc} 
Table 1. Characteristics of respondents & \\
\hline Demographic features & $\begin{array}{c}\text { Clinical } \\
\text { teachers }\end{array}$ & $\begin{array}{c}\text { Medical Educ. } \\
\text { specialists }\end{array}$ \\
\hline $\begin{array}{l}\text { University } \\
\text { Type I }\end{array}$ & $85 \%$ & $77 \%$ \\
Type II & $15 \%$ & $23 \%$ \\
& Sex & \\
Female & $33 \%$ & $67 \%$ \\
Male & $67 \%$ & $33 \%$ \\
Work experience & & \\
<5 years & $15.9 \%$ & 6 \\
5-10 years & $23.8 \%$ & 10 \\
11-15 years & $17.6 \%$ & 6 \\
16-20 years & $18.1 \%$ & 9 \\
$>20$ years & $24.7 \%$ & 11 \\
\hline
\end{tabular}




\begin{tabular}{|c|c|c|c|c|c|}
\hline \multicolumn{2}{|l|}{ Clinical education topics } & $\begin{array}{l}\text { Faculty } \\
\text { skills } \\
\mathrm{M}(\mathrm{SD})\end{array}$ & $\begin{array}{c}\text { Faculty needs } \\
\text { M (SD) }\end{array}$ & $\begin{array}{l}\text { FDP designers } \\
\mathrm{M}(\mathrm{SD})\end{array}$ & $\begin{array}{c}\text { Students (Teachers } \\
\text { evaluation) } \\
\text { M (SD) }\end{array}$ \\
\hline \multicolumn{6}{|c|}{ Objectives of clinical education } \\
\hline \multirow{3}{*}{ Affective objectives } & Communication skills, history taking & $3.34(0.57)$ & $3.56(1.35)$ & $4.66(0.61)$ & $4.47(0.64)$ \\
\hline & Professionalism & $3.19(0.68)$ & $3.87(1.25)$ & $4.73(0.49)$ & $4.67(0.55)$ \\
\hline & Emotional intelligence & $2.50(0.97)$ & $3.77(1.00)$ & $4.23(0.72)$ & $4.39(0.67)$ \\
\hline Cognitive objectives & Clinical reasoning & $3.34(0.93)$ & $3.55(1.06)$ & $4.33(0.81)$ & - \\
\hline Psychomotor objective & Procedure training & $3.59(0.82)$ & $3.31(1.23)$ & $4.017(0.86)$ & $4.42(0.62)$ \\
\hline System objectives & $\begin{array}{l}\text { Management and Leadership in Clinical } \\
\text { Education }\end{array}$ & $3.07(0.69)$ & $3.47(1.11)$ & $4.2: 3(0.69)$ & - \\
\hline \multicolumn{6}{|c|}{ Clinical education settings } \\
\hline \multirow[t]{4}{*}{ Service Setting } & In-patient ward & $3.11(0.83)$ & $3.72(1.27)$ & $4.45(0.67)$ & $4.40(0.59)$ \\
\hline & Out-patient department & $3.38(0.76)$ & $3.38(1.15)$ & $4.512(0.59)$ & $4.46(0.64)$ \\
\hline & Emergency department & $3.39(0.73)$ & $3.26(1.24)$ & $4.14(0.84)$ & $4.41(0.59)$ \\
\hline & Operation room & $2.30(1.29)$ & $2.45(1.39)$ & $3.8 .5(0.97)$ & $4.53(0.54)$ \\
\hline \multirow[t]{3}{*}{ Protected Setting } & Morning report & $3.33(0.7)$ & $3.25(1.22)$ & $4.02(0.78)$ & $3.91(1.01)$ \\
\hline & Grand round & $3.23(0.78)$ & $3.20(1.20)$ & $3.8: 3(0.76)$ & $4.74(0.52)$ \\
\hline & Journal club & $3.21(0.78)$ & $3.24(1.23)$ & $3.8: 5(0.81)$ & $4.23(0.75)$ \\
\hline
\end{tabular}

$\mathrm{M}=$ mean score

$\mathrm{SD}=$ standard deviation

need according to the two parts of the questionnaire is as follows.

Objectives of clinical education: Findings in this section showed that in "management and leadership in clinical education", the current skill (3.07) has the most distance from the need (3.85) and the least gap is in "Communication skills and history taking" and in "Procedure training" the positive gap showed that need is less than teacher's

\section{skill (Fig. 1).}

Clinical education settings: Based on the analysis of the questionnaires, "ground round"' has the most gap between current status (3.98) and amount of need (3.51). Of course, this difference is in the positive direction, that is, the skill level is higher than the need. But "in-patient ward" has the most negative gap between current status (3.75) and amount of need (4.08) (Fig. 2).

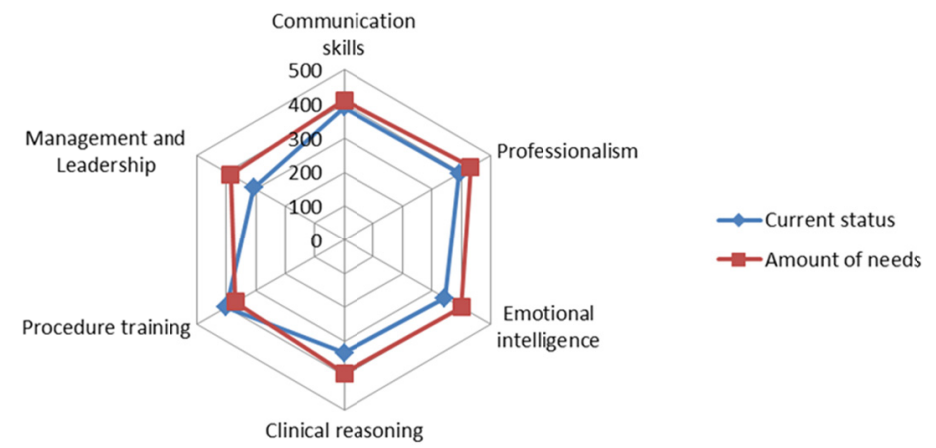

Fig. 1. "Objectives of clinical education" in the current status and amount of needs

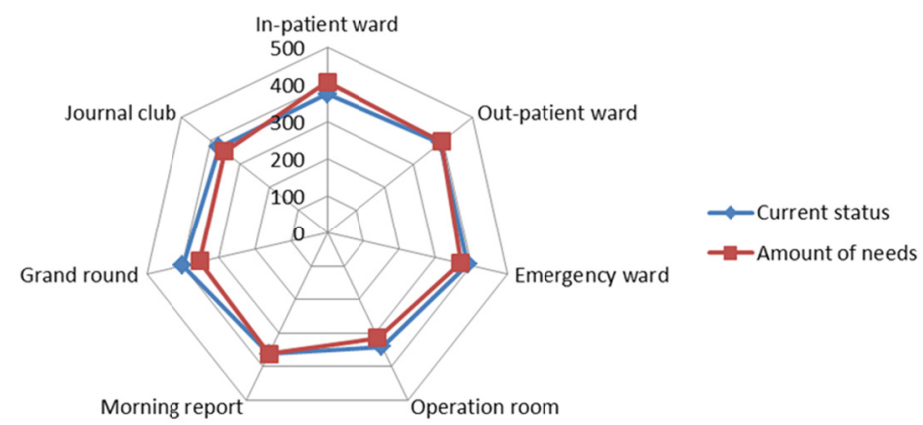

Fig. 2. "Clinical education settings" in the current status and amount of needs 
Table 3 presents the estimated gap, chi-square, and Cramer's correlation coefficient between the current status and the announced needs. It should be pointed out that the obtained chi-square indicates the difference in concentration of responses meaning that participants assessed the need for teaching professionalism as "highly needed" and their present skill as moderate. Investigation of the degree of correlation between the "amount of need" and the "skill level" demonstrated a Cramer's coefficient of 0.18-0.34 $(\mathrm{P}<0.05)$; hence, it may be concluded that there is a correlation between the current status and the announced needs in all subjects.

\section{Discussion}

This study explored clinical faculties' needs from their own viewpoint and that of FDP planners. It also investigated faculties' skill levels from their own viewpoint and also from students' perspectives. A successful "needs assessment" ought to focus on four principles: the needs assessment content should be developed on the basis of organizational context, valid and reliable data should be collected from different sources, the needs of representatives of all community parties ought to be considered, and the beneficiaries should contribute to all phases of the needs assessment process (18).

From the clinical faculties' perspective, all clinical teaching methods except teaching in OR obtained a score $>3$. The lower-than-standard score of the operating room is due to the fact that some medical specialties do not re- quire working and teaching in the Operating Room (OR). The five first priorities of clinical faculties included: teaching of professionalism, the use of emotional intelligence in the clinical setting, clinical rounds in the inpatient wards, teaching with simulation, and teaching of communication skills and histiory taking. Medical education faculties also believed that clinical faculties need to be developed and promoted in all subjects pertaining to clinical teaching and evaluation. Their five first priorities were: teaching professionalism, teaching of communication skills and history taking, teaching in the clinical setting, clinical rounds in the in-patient wards, and the concept of clinical reasoning and its teaching.

A significant issue in data analysis was the fact that teaching professionalism was the first and most important priority of "clinical needs teaching" from the perspectives of both clinical faculties and FDP designers. In the past, the term "faculty" was used to refer to a specialty in a specific field that transmitted knowledge to apparently unknowledgeable students. Nonetheless, faculties today pass over the traditional borders of their profession and require something beyond a teacher's bogey. This includes professional manners and role model at both individual and organizational levels (19). Accreditation Council for Graduate Medical Education (ACGME) has emphasized that six main competencies ought to be present in all teaching and evaluation programs for residents with professionalism being one of the six. Professional competency includes conscious and accurate use of knowledge,

Table 3. Mean scores of gaps, chi-square and Cramer's V

\begin{tabular}{|c|c|c|c|c|c|c|}
\hline \multicolumn{2}{|c|}{ Clinical education topics } & \multirow{2}{*}{$\begin{array}{c}\text { Current status } \\
\text { (Faculty } \\
\text { Skills+ Teachers } \\
\text { evaluation results) } \\
\mathrm{M} \\
\end{array}$} & \multirow{2}{*}{$\begin{array}{c}\text { Amount of } \\
\text { needs } \\
\text { faculty }+ \text { FDP } \\
\text { designers needs } \\
\text { M } \\
\end{array}$} & \multirow{2}{*}{$\begin{array}{c}\text { Gap } \\
\text { (skill-need) }\end{array}$} & \multirow{2}{*}{$\begin{array}{l}\text { Chi-square } \\
\left(\mathrm{X}^{2}\right)\end{array}$} & \multirow{2}{*}{$\begin{array}{c}\text { Cramer's } \\
\text { V }\end{array}$} \\
\hline Objectives of clinic & education & & & & & \\
\hline \multirow{4}{*}{ Affective } & Communication skills, history & 3.90 & 4.11 & -0.21 & $X^{2}=41.63$ & 0.23 \\
\hline & taking & & & & $\mathrm{P}<0.001$ & $\mathrm{P}<0.001$ \\
\hline & Professionalism & 3.93 & 4.30 & -0.37 & $\begin{array}{l}\mathrm{X}^{2}=50.46 \\
\mathrm{P}<0.001\end{array}$ & $\begin{array}{c}0.22 \\
\mathrm{P}<0.001\end{array}$ \\
\hline & Emotional intelligence & 3.44 & 4.00 & -0.36 & $\begin{array}{l}\mathrm{X}^{2}=89.90 \\
\mathrm{P}<0.001\end{array}$ & $\begin{array}{c}0.28 \\
\mathrm{P}<0.001\end{array}$ \\
\hline Cognitive & Clinical reasoning & 3.34 & 3.94 & -0.60 & $X^{2}=1.06$ & 0.34 \\
\hline Objectives & & & & & $\mathrm{P}<0.001$ & $\mathrm{P}<0.001$ \\
\hline $\begin{array}{l}\text { Psychomotor } \\
\text { objective }\end{array}$ & Procedure training & 4.00 & 3.69 & 0.31 & $\begin{array}{c}X^{2}=89.94 \\
P<0.001\end{array}$ & $\begin{array}{c}0.29 \\
\mathrm{P}<0.001\end{array}$ \\
\hline System objectives & $\begin{array}{l}\text { Management and Leadership in } \\
\text { Clinical Education }\end{array}$ & 3.07 & 3.85 & -0.78 & $\begin{array}{c}\mathrm{X}^{2}=83.64 \\
\mathrm{P}<0.001\end{array}$ & $\begin{array}{c}0.28 \\
\mathrm{P}<0.001\end{array}$ \\
\hline \multicolumn{7}{|c|}{ Clinical education settings } \\
\hline \multirow[t]{4}{*}{ Service Setting } & In-patient ward & 3.75 & 4.08 & -0.33 & $\begin{array}{l}\mathrm{X}^{2}=1.01 \\
\mathrm{P}<0.001\end{array}$ & $\begin{array}{c}0.31 \\
\mathrm{P}<0.001\end{array}$ \\
\hline & Out-patient ward & 3.92 & 3.95 & -0.03 & $\begin{array}{c}\mathrm{X}^{2}=36.71 \\
\mathrm{P}=0.002\end{array}$ & $\begin{array}{c}0.18 \\
\mathrm{P}<0.001\end{array}$ \\
\hline & Emergency ward & 3.90 & 3.70 & 0.20 & $\begin{array}{l}\mathrm{X}^{2}=51.94 \\
\mathrm{P}<0.001\end{array}$ & $\begin{array}{c}0.22 \\
\mathrm{P}<0.001\end{array}$ \\
\hline & Operation room & 3.41 & 3.15 & 0.26 & $\begin{array}{l}\mathrm{X}^{2}=1.18 \\
\mathrm{P}<0.001\end{array}$ & $\begin{array}{c}0.34 \\
\mathrm{P}<0.001\end{array}$ \\
\hline \multirow[t]{3}{*}{ Protected Setting } & Morning report & 3.62 & 3.63 & -0.01 & $\begin{array}{l}\mathrm{X}^{2}=57.57 \\
\mathrm{P}<0.001\end{array}$ & $\begin{array}{c}0.23 \\
\mathrm{P}<0.001\end{array}$ \\
\hline & Grand round & 3.98 & 3.51 & 0.47 & $\begin{array}{l}\mathrm{X}^{2}=60.97 \\
\mathrm{P}<0.001\end{array}$ & $\begin{array}{c}0.25 \\
\mathrm{P}<0.001\end{array}$ \\
\hline & Journal club & 3.72 & 3.54 & 0.18 & $\begin{array}{l}\mathrm{X}^{2}=74.97 \\
\mathrm{P}<0.001\end{array}$ & $\begin{array}{c}0.26 \\
\mathrm{P}<0.001\end{array}$ \\
\hline
\end{tabular}


technical skills, clinical reasoning, communication skills, and feelings and values reflected in physician's daily performance to serve individuals and the community (20). Byszewski of Ottawa accomplished a study on medical students' perception of professionalism and its promotion method and concluded that professionalism should be the crux of the syllabus for general physicians and a component of students' and faculties' evaluation process. Moreover, FDP in this field should focus on activities that enable them to role modeling of professional features like empathy, respect, continuous self-improvement, and altruism (21). A systematic review by Cornelia et al. on assessing the quality of clinical teachers demonstrated that the questionnaires used to assess the clinical faculties' quality of teaching mostly concentrated on teaching, role modeling, providing feedback, and being supportive (22). This finding is consistent with the results of our study suggesting that scholars and researchers in medical education also pay due attention to the quality of teaching, role modeling, and/or observation of professionalism on the part of faculties and prioritize them.

Faculties expressed their level of skills in any of the clinical teaching methods using a scale developed on the basis of the Dreyfus model of skill acquisition. One of the greatest capabilities of FDP authorities is the ability to extract their needs on the basis of self-assessment. The faculties and authorities get aware of their strengths and weaknesses in self-assessment. The weak points or learning needs form the foundation and sine qua none of the onsets of a standard educational planning process (23).

Clinical faculties reported their highest level skill in procedure training and the lowest level in emotional intelligence, whereas students reported their highest level skill in holding grand rounds and the lowest level in the morning report. Of course, students introduced emotional intelligence as the third skill with a low score. The second priority of clinical faculties' needs and the lowest score of current skill was emotional intelligence. This term refers to the ability, capacity or skill in perceiving, measuring, and managing one's emotions and that of others and the use of this information in guiding one's thoughts and actions (24). Indeed, it may be postulated that emotional intelligence and communication skills are a subset of professionalism that was investigated separately due to their importance.

In this study, both clinical teaching needs from clinical and medical faculties' perspective and the level of skills from faculties' perspective, also the results of faculties' evaluation that is, in fact, the rate of skills from students' viewpoints were elucidated and compared. The findings revealed that the greatest gap occurred between the current status and the amount of need in management and leadership in the clinical setting. In a number of cases, the rate of skills was greater than the number of needs. Holding grand rounds and procedure training acquired the highest scores. Management and leadership are among the prerequisites of a good physician. The definition provided by Noren \& Kindig clearly determines these concepts and their importance. "Management and leadership have two distinct roles and both are essential to the success of any enterprise. Management means coping with complex organizations and ensuring that things run well, that everyday problems are dealt with, and that there is a steady and continuous performance of the whole. Leadership, on the other hand, involves visioning and motivating others to achieve a preferred vision. It requires dealing with change, often unanticipated, unplanned change- whether it comes from external forces, such as government, or from internal forces such as new medical technologies and the resultant but unanticipated ethical dilemmas (25)". According to the study by Rouhani et al. on UK medical students' perceptions, attitudes, and interests toward medical leadership, students show much interest in learning managerial and leadership skills whereas they receive weak teaching and the gap between the number of needs and the current status (26). Various studies have confirmed the correlation between leadership and the rate of achieving the basic goals of healthcare organizations. These goals cover patient satisfaction as well as the quality of care $(27,28)$. Despite the important role of management and leadership, nothing exists in medical students' education to convert them to leaders (25). It may be concluded that the abovementioned reason is the main cause of the gap between the rate of current skills and the needs of clinical faculties, management, and leadership in the clinical setting.

\section{Strengths and weaknesses}

One strong point of this study was the smart development of questionnaires on the basis of four important domains of goals in clinical education and additionally, considering two principal settings in clinical education, i.e., service setting and protected setting. It may be asserted that the use of the Dreyfus model for measuring the present level of skills of faculties is one of the innovations of the present study.

One limitation of the present study was the presence of intervening variables like the effect of the governing atmosphere of the university, clinical field, and previous experiences on the results of needs assessment. An attempt was made to overcome this effect as far as possible through sampling from type 1 and type 2 universities, various clinical wards, and different work experiences. This enhances the generalizability of the findings of the study.

Next limitation of the present study was the ambiguities in the weight and importance of each item so that the generalizability of the results to other persons and settings for faculty development was jeopardized. Such as in- operation room training that is not common to all disciplines; also some medical majors are highly important in the emergency department while others are less significant. Another weak point was the lack of the use of the results of faculty evaluations from all medical universities under study. This was not possible due to information confidentiality and the inaccessibility of information. It is recommended that a more precise and comprehensive questionnaire be developed and administered on the basis of principal competencies required for any of the teaching situations. Using the results of such a questionnaire, more accurate and effective programs may be developed for faculty development. 


\section{Conclusion}

Graphite and diamond are both composed of pure carbon with no other element in their structure. So, they have the same nature; yet, due to differences in the arrangement of carbon atoms in these two substances, they show quite different characteristics. In the diamond formula, each carbon atom is linked to four neighboring carbon atoms via univalent links producing a beautiful four-sided structure. On the contrary, graphite is very soft and brittle with very low hardness. This dark substance has no apparent similarity to its brother, i.e., diamond, which has a multilayered structure. In each layer, each carbon atom is attached to three neighboring atoms. Diamond with one extra link shows much greater superiority. The same is true with needs assessment; that is, the use of one or more extra sources may lead us to preset goals and ultimately, to diamond goals preventing us from being strangled in graphite traps. Professionalism was the most important and prioritized declared educational need highlighted by faculties and FDP Designers. In addition to promoting their professional skills, faculties ought to be able to teach them to their students preparing them to become good future physicians and accept the roles of therapist, teacher, researcher, supporter, and manager. Our findings suggested that the greatest gap occurred between faculties' level of skills and the announced needs in clinical management and leadership. However, leadership is directly correlated with achieving vital goals of healthcare organizations including patient safety, reduced errors, promoted clinical care, etc. Our results and those of other studies indicate that there is a need for comprehensive clinical faculty development programs in professionalism and management to be developed by decision-makers.

\section{Acknowledgment}

The researchers would like to express their gratitude to the professors and students participating in the study.

\section{Conflict of Interests}

The authors declare that they have no competing interests.

\section{References}

1. Behnamfar R, Mostaghaci M. Residents and Medical Students' Satisfaction with Journal Club Meetings at Shahid Sadoughi University of Medical Sciences. Iran J Med Educ. 2016;16:379-87.

2. Tohidi S, Karimi Moonaghi H. Self-learning Module in Medical Education: A Review of the Literature. Iran J Med Educ. 2016;16:7283.

3. Esmaeili MR, Hozni SA, Mosazadeh B, Zavareh A. Good teacher's characteristics and its influence on dental students academic motivation in guilan university of medical sciences. Res Med Educ. 2017;9(3):18-10.

4. Emami H, Aghdasi M, Asousheh A. Electronic learning in medical education. Res Med Educ. 2009;33(2).

5. Delaram M, Reisi Z, Alidusti M. Strengths and Weaknesses of clinical education from the viewpoints of nursing and midwifery students in Shahrekord university of medical sciences, Shahrekord, Iran. Qom Univ Med Sci J. 2012;6(221).

6.Zodpey S, Sharma A, Zahiruddin QS, Gaidhane A, Shrikhande S. Faculty development programs for medical teachers in India. J Adv Med Educ Prof-2016;4(2):97-101.

7. Ahmady, Soleiman. Faculty development in medical education: a comprehensive approach. Institutionen för lärande, informatik, management och etik, LIME/Department of Learning, Informatics, Management and Ethics (Lime), 2009.

8. Tootoonchi M, Yamani N, Changiz T, Yousefy A. Research priorities in medical education: A national study. J Res Med Sci. 2012;17(1):83.

9. Kojuri J, Amini M, Karimian Z, Dehghani MR, Saber M, Bazrafcan L et al. Needs assessment and evaluation of a short course to improve faculties teaching skills at a former World Health Organization regional teacher training center. J Adv Med Educ Prof. 2015;3(1):1-8.

10. Lancaster JW, Stein SM, MacLean LG, Van Amburgh J, Persky AM. Faculty development program models to advance teaching and learning within health science programs. Am J Pharm Educ. 2014;78(5):99.

11. Adkoli BV, Al-Umran KU, Al-Sheikh MH, Deepak KK. Innovative method of needs assessment for faculty development programs in a Gulf medical school. Educ Health (Abingdon). 2010;23(3):389.

12. Farley H, Casaletto J, Ankel F, Young KD, Hockberger R. An Assessment of the Faculty Development Needs of Junior Clinical Faculty in Emergency Medicine. Acaad Emerg Med. 2008;15(7):664-8

13. Manzoor I, Zeeshan S, Iqbal A, Sarfraz F. Needs Assessment For Establishing Faculty Development Program In A Private Medical College At Lahore. J Ayub Med Coll Abbottabad. 2018;30(4):539-43.

14. McSparron JI, Huang GC, Miloslavsky EM. Developing internal medicine subspecialty fellows' teaching skills: a needs assessment. BMC Med Educ. 2018;18(1):221

15. Adams J BB, Becker F, et al. Effectiveness and acceptability of parental financial incentives and quasi-mandatory schemes for increasing uptake of vaccinations in preschool children: systematic review, qualitative study and discrete choice experiment. Southampton (UK): NIHR Journals Library; 2015 Nov. (Health Technology Assessment, No. 19.94.) Chapter 6, Triangulation and integration of results. Available from: https://www.ncbi.nlm.nih.gov/books/ NBK326956/.

16. Carter N, Bryant-Lukosius D, DiCenso A, Blythe J, Neville AJ. The use of triangulation in qualitative research. Oncol Nurs Forum. 2014;41(5):545-7.

17. Dean AG, Sullivan KM, Soe MM. "OpenEpi: open source epidemiologic statistics for public health, version." (2013). [Available from: http://www.openepi.com/SampleSize/SSPropor.htm.

18. Cary Cuiccio MHS. Needs Assessment Guidebook. The State Support Network: American Institutes for Research under U.S Department of Education; May 2018. Available from: https://statesupportnetwork.ed.gov/resources/needs-assessment-guide book.

19. Kumar D. Discussing the Undiscussed: What Ingredients are Missing in Faculty Udevelopment Programs? Res Dev Med Educ. 2018;7(2):64-7.

20. Seif-Farshad M, Bazmi S, Amiri $\mathbb{F}$, Fattahi F, Kiani M. Knowledge of medical professionalism in medical students and physicians at Shahid Beheshti University of Medical Sciences and affiliated hospitals-Iran. Medicine. 2016;95(4.5):e5380.

21. Byszewski A, Hendelman W, McGuinty C, Moineau G. Wanted: role models--medical students' perceptions of professionalism. BMC Med Educ. 2012;12:115.

22. Fluit CR, Bolhuis S, Grol R, Laan R, Wensing M. Assessing the quality of clinical teachers: a systematic review of content and quality of questionnaires for assessing clinical teachers. J Gen Intern Med. 2010;25(12):1337-45.

23. Matava CT, Rosen D, Siu E, Bould DM. eLearning among Canadian anesthesia residents: a survey of podcast use and content needs. BMC Med Educ. 2013;13:59

24. Mackay SJ, White P, McNullty JP, Lane S, Lewis SJ. A benchmarking and comparative analysis of emotional intelligence in student and qualified radiographers: an international study. J Med Radiat Sci. 2015;62(4):246-52.

25. Collins-Nakai R. Leadership in medicine. Mcgill J Med. 2006;9(1):68-73

26. Rouhani MJ, Burleigh EJ, Hobbis C, Dunford C, Osman NI, Gan C, et al. UK medical students' perceptions, attitudes, and interest toward medical leadership and clinician managers. Adv Med Educ Pract. 2018;9:119-24

27. West M, Armit K, Loewenthal L, Eckert R, West T, Lee A. Leadership and leadership development in health care: the evidence base.. London: Faculty of Medical Leadership and Management; 2015:2-4. feb-2015. Available from: https:/www.kingsfund.org.uk/ 
Needs assessment of clinical teachers

sites/default/files/field/field_publication_file/leadership-leadershipdevelopment-health-care-.

28. Yamani N, Moosavi SA, Alizadeh M, Khorvash F, Ghiasi M. A 360-

degree performance evaluation of emergency medicine ward in Alzahra Hospital. J Pak Med Assoc. 2012;62(3 Suppl 2):S13-7. 